\title{
Reflective Journal as A Self-Directed And Sustainable Professional Development Tool For Pre-Service Teachers: A Case Study In English Language Education Study Program ${ }^{1}$
}

\author{
Atalya Agustin \\ atalya.agustin@uph.edu \\ Faculty of Education, Universitas Pelita Harapan
}

\begin{abstract}
Teaching practice is one among many programs in teachers training which focuses on having a professional preparation for work. In this program, student-teachers are asked to improve their skills through teaching actual students and engaging with school environment. Moreover, they are also building their own knowledge based on the improved teaching and learning process. It is crucial for them as pre-service teachers to encounter such experience. This meaningful theory and experience-based insights are possible to obtain if the studentteachers possess the commitment of self-reflection. There is likely a big chance that this action will be perpetual because of this personal initiative. This study aims to analyze the use of reflective journal as pre-service teachers' professional development tool, their attitude towards reflective journal, as well as the strength and challenges arise related to the use of reflective journal during their teaching practice. The type of the research is a qualitative case study research. The data collection techniques being used are questionnaire and Focus Group Discussion (FGD). Moreover, the technique of analyzing the data was Miles and Huberman concept of data reduction, data presentation, and conclusion drawing. The results of this research will be presented in a descriptive-narrative manner by describing and discussing the data of the research.
\end{abstract}

Keywords: Reflective Journal, Self-Directed, Professional Development

Received date: 14 April 2019

Article Info

Revised date: 3 Mei $2019 \quad$ Accepted date: 17 Mei 2019

\section{INTRODUCTION}

Professional development has been the central concern of teachers at any level. Junior and senior teacher both need intentional professional preparation for work. Teachers need to be kept updated and aware of best practices and possible challenges in classroom setting. They are also encouraged to achieve goals and pursue excellence. Professional development is crucial to prepare teachers to be responsible and possess better classroom practices

Teachers' professional development are not only for in-service teachers. It is also for preservice teachers. The previous statement seems a bit irrelevant because they do not even get their teaching credential yet. Thus, they do not have their own class. But, during their teacher training program, student teachers have been exposed with hands-on experience in teaching and learning. They teach and engage with real classroom and real students. Teachers cannot heavily depend on their knowledge which they get from teacher training program, but they also have to inquire and reflect on their own practices. Maximizing student teachers' experience and growth through this process is indeed a professional development program.

Student teachers or pre-service teachers will be best equipped if they are also exposed to professional development as early as possible. Drawing from literature, there are three aspects which needs to be focused related to professionally developing a student teacher which are participants' reactions, participants' learning, and participants' use of new knowledge or skills. Professional Development for in-service teachers should also consider all of the aspects (Guskey, 2002).

\footnotetext{
${ }^{1}$ Presented at the 2018 TEFLIN International Conference at Universitas Negeri Makassar, $12^{\text {th }}-14^{\text {th }}$ July 2018.
} 
There are some ways to conduct teacher's professional development for pre-service teachers during their training or teaching practice. One easy, simple, effective, and efficient way to do that is in the form of reflection. Student teachers will reflect on their teaching practices, process them, and finally determine whether he/she will change his/her belief or behavior towards teaching and learning. This transformation will only be meaningful if the teachers are willing to do it. The shift from knowledge into action is possible if the teachers have autonomy to respond to the result of the reflection. Meng (2014) mentioned clearly that self-directed professional development, which in this case is reflection, is considered an effective approach to professional development which is related to teaching practices. Professional development in this practice is building a reflective habit towards improved teaching and learning process which begins in the teaching practicum.

\section{LITERATURE}

Professional development is crucial for both teachers and student teachers. It is very important because whether the teacher can fulfill complicated and challenging requirements in the school setting really relies on their professional preparation (Lingam, Lingam, \& Raghuwaiya, 2014). The earlier student teachers get exposed to professional development the better they will become professional teachers. As a matter of fact, their undergraduate studies are also professional development programs. However, teachers-to-be need to be more autonomous in their professional preparation journey. There are some criteria of a self-directed person which are full of initiative, having self-control, willing to do something, doing self-assessment and always wanting to investigate to get some information (Minnot, 2010). Self-reflection can be one effective and efficient way to keep up with this expectation.

Reflection is crucial for teachers and teachers-to-be in every context and situation. Reflection gives transformation or reformation of initial knowledge into expected outcome (Moon, 2005). Through reflection, teachers can evaluate and improve teaching and learning process. Teachers understand their responsibilities and find ways to be better. What is clear from literature such as that by Shandomo (2010), one significant result of the cumulative reflection is all about the perception of the essential role that reflection can take part in extended professional development. Reflective journal as one of the tools to do self-reflection can help teacher to record and put their reflection into a tangible and measurable form. Reflective journal writing will work best if being incorporated with learning process to create reflective community and reflective leaders (Göker, 2016). Microteaching class can be one of the places to build reflective habit for each teacher-to-be. However, this reflective journal must be based on evidence (Ferrel, 2013). Meaningful self-directed and sustainable professional development through reflective journal writing is possible when the solid and real data is deeply and thoroughly analyzed and elaborated with the perspective of the teachers.

\section{RESEARCH METHODOLOGY}

This research is a qualitative case study research which has 23 students who are majoring on English Language Education as the subject. These students are on their teaching practice program as senior students. Based on Sternhouse (1985 in Bassey, 1999), this research is educational case study type which improves and adds more ideas for educational practices through the development of theory or thought through logical and thoughtful documentation of data. The subjects were chosen using purposive sampling. Purposive sampling, according to Mulyana (2010) is choosing samples purposively where researchers can find samples who are willing to give data. The students being chosen are the ones who are senior students and in the middle of their teaching practice.

Data collection was held in a natural setting using questionnaire. It was conducted after they have finished their teaching practice and written their reflections. Researchers also conducted Focus Group Discussion (FGD) to get in-depth information about students' attitude towards reflective journals.

Researchers analyzed the data by examining all the data collected through questionnaire and Focus Group Discussion (FGD). Student teachers' perspectives and attitudes will be collected through all two instruments. Reflective journal is used to collect data from student teachers' reflection. Moreover, a Focus Group Discussion is conducted to gather deeper data from the students.

There are three steps of qualitative data analysis employed in this study which are data reduction, data presentation and conclusion drawing. Researchers reduce the data using the items related 
to theory of self-directed attitude by Minnot (2010) and continuous professional development by Lessing and de Witt (2017). Data presentation will be described in descriptive narrative manner. Finally, the conclusion is drawn through the triangulation between the data from observation, reflection, and FGD.

\section{FINDINGS AND DISCUSSION}

This study has identified 3 spheres/domains regarding writing reflective journal (RJ) as a selfdirected and sustainable professional development program. Those three domains are the use of reflective journal, the attitude of the student teachers towards reflective journal and the strengths and challenges arise during the process of writing reflective journal in the teaching practicum.

Those three domains will present to us whether reflective journal would help equipping the student teachers through a self-directed and sustainable manner. In the first domain, there are some aspects which will be further investigated. These aspects are related to purpose of writing reflective journal as follow:

Table 1. First Domain of Writing Reflective Journal

\section{First Domain}

The Use of Reflective Journal

1. Recalling critical moment in their teaching and learning process

2. Recording student teachers' responses or reactions

3. Expressing their thought and feeling towards the critical moment

4. Comparing between experiences (previous and present)

5. Helping the student teachers to record student performance or achievement

6. Recording students' physical or emotional wellbeing

7. Recording the impact of teaching and learning on students

8. Helping them to acquire the intended pedagogical knowledge or skill

9. Helping them to learn from their experiences

\section{(Source: Author)}

Meanwhile, there are several aspects to measure the second domain which is the attitude towards reflective journal. In this part, there is not only student teachers' attitudes which are taken into consideration, but also the underlying beliefs behind the attitudes. The aspects are presented in the table below:

Table 2. Second Domain of Writing Reflective Journal

\section{Second Domain}

Student Teachers' Attitude Towards Reflective Journal

1. agreed to write things that went badly in the classroom

2. also agreed to write things that went well

3. they have written some resolution in their reflective journal

4. writing $\mathrm{RJ}$ is important

5. believes that writing $\mathrm{RJ}$ is meaningful for them

(Source: Author)

The last domain is strengths and challenges arise when student teachers were writing RJ. There are some statements indicating the strength and challenges when they were writing reflective journal as follows:

Table 3. Third Domain of Writing Reflective Journal

\section{Third Domain}

The Strength and Challenges in Writing Reflective Journal

1. RJ help them to recognize their strength and weaknesses

2. helps them to rationale critical moments and respond to them

3. the rubrics helped guiding them 
Reflective Journal as A Self-Directed And Sustainable Professional Development Tool For Pre-Service Teachers: A Case Study In English Language Education Study Program (Atalya Agustin)

4. there was guidance from mentor or supervisor to write RJ

5. she/he will keep writing RJ without being asked

6. writing RJ helps them to plan teaching and learning process

7. helps to bring change in terms of knowledge, skill and most importantly, perspective

8. writing RJ could strengthen their calling as teachers

(Source: Author)

The following explanation will identify and describe the use of reflective journal according to the student teachers based on the three domains.

\section{The Use Of Reflective Journal}

This domain will present to us some statement related to the nature, purpose, and function of reflective journal which are seen from student teachers' eyes. For better visual representation, please see this following Figure 1.

\section{THE USE OF REFLECTIVE JOURNAL}

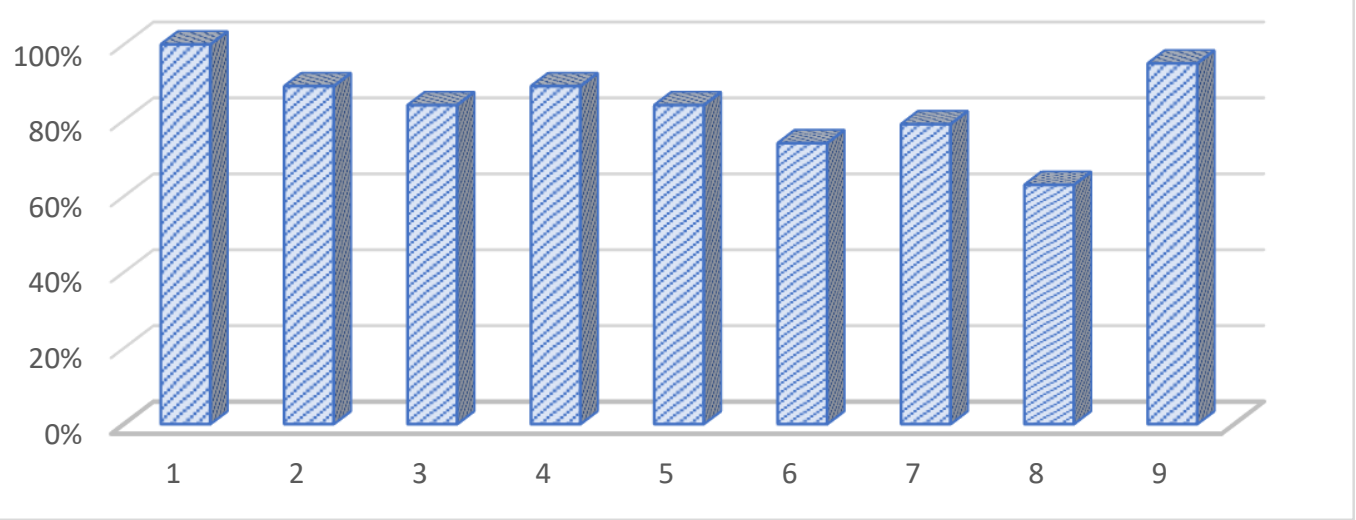

Figure 1. The Use of Reflective Journal

Annotation:

1. Recalling critical moment in their teaching and learning process

2. Recording student teachers' responses or reactions

3. Expressing their thought and feeling towards the critical moment

4. Comparing between experiences (previous and present)

5. Helping the student teachers to record student performance or achievement

6. Recording students' physical or emotional wellbeing

7. Recording the impact of teaching and learning on students

8. Helping them to acquire the intended pedagogical knowledge or skill

9. Helping them to learn from their experiences

The first domain All students (100\%) agree that writing RJ could help them to recall critical moment in their teaching and learning process. Not only doing so, but the student teachers also could record their responses or reactions through RJ. This fact really shows that RJ could help them to be motivated in reflecting what they have been doing. Meanwhile, expressing their thought and feeling towards the critical moment can also be done through RJ. The interesting fact is not all the student teachers (89\%) felt this way. This is probably because it was not easy to express all thought and feeling even though they remember what happened during teaching and learning process.

Writing RJ also helps the student teachers to do self- assessment. $84 \%$ of the participants said that RJ help them to see the causes of the events/moments and also the consequences which follows. $89 \%$ of the student teachers could compare between experiences (previous and present) and also could think of things they could do differently by writing RJ. Moreover, writing RJ also helps the student teachers to record student performance or achievement (84\%), record students' physical or emotional 
wellbeing (74\%), and record the impact of teaching and learning on students (79\%). These responses are aligned with the criteria of wanting to get information from the students.

In this domain, some responses of the student teachers also show that writing RJ could make them maintain their best practices and keep learning. Lessing and de Witt (2007) state that to be able to have a continuous or sustainable professional development, a teacher should have a shift of what he/she believes, manner, understanding, ability, and confidence in the daily teaching and learning practice, awareness in the importance of the profession and life-long learning. This means that teacher understands the urgency of continuous learning from daily teaching and learning activity, is willing to change, and building the habit of long-life learning.

Moreover, $63 \%$ of the student teacher mentioned that RJ somehow helps them to acquire the intended pedagogical knowledge or skill. The fact that not all student teachers felt the same thing is probably because they are not sure what pedagogical knowledge or skill they will focus to grow in in their practicum. Furthermore, many student teacher (95\%) stated that RJ help them to learn from their experiences. They mentioned that they learned many things such as teaching skills, classroom management, how to apply the approach and method in teaching English, reflect and improve evaluation skills, writing skill, strategy of learning, questioning skill, and skill to understand students' behavior. Being reflective could help teachers to cope with difficult situation because teachers understand the contexts more in the classroom and are able to find creative and innovative strategies to solve classroom problem (Minnot, 2010). Even though, this research's context, microteaching class, is somehow more structured and limited compared to real classroom, but still there are many things that we can learn and process from the teaching and learning process.

\section{Student Teachers' Attitudes Towards Reflective Journals}

This domain related to the beliefs and attitudes showed by the student teachers in regards of writing reflective journal. The figure below will show the percentage of each statement.

\section{STUDENT TEACHERS' ATTITUDE TOWARDS REFLECTIVE JOURNAL}

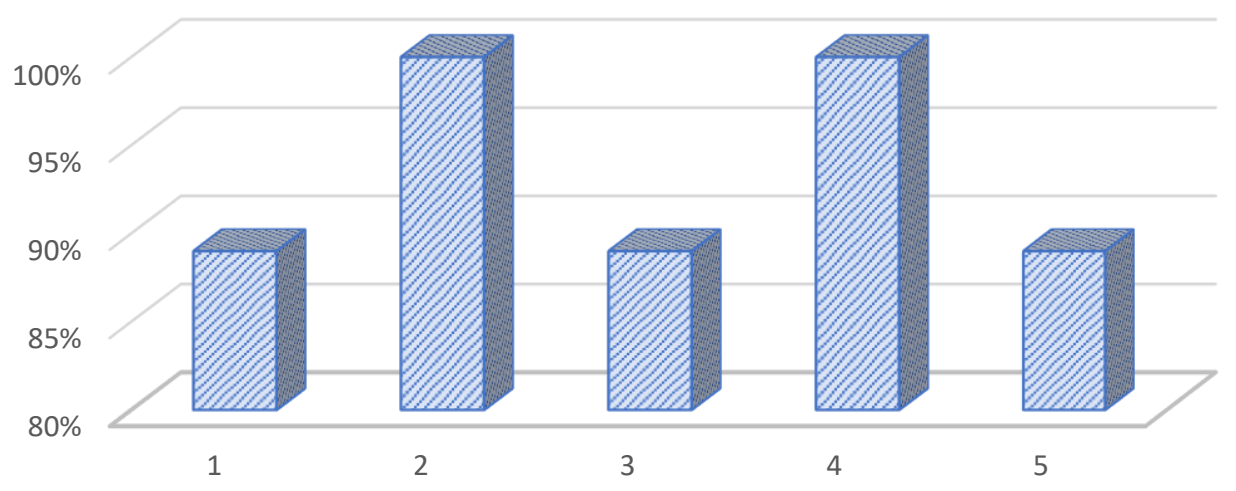

Figure 2. The Student Teachers' Attitude towards Reflective Journal

Annotation:

1. agreed to write things that went badly in the classroom

2. also agreed to write things that went well

3. they have written some resolution in their reflective journal

4. writing $\mathrm{RJ}$ is important

5. believes that writing $\mathrm{RJ}$ is meaningful for them

The second domain is the attitude towards reflective journal. This part will examine student teachers' behaviors, manners, or responses towards writing RJ. The responses will also be categorized into two aspects which are self-directed and sustainable. This study identified that the student teachers believes that they should record critical moments which are crucial for their evaluation through RJ. 89\% student teachers agreed to write things that went badly in the classroom and $100 \%$ of them also agreed 
Reflective Journal as A Self-Directed And Sustainable Professional Development Tool For Pre-Service Teachers: A Case Study In English Language Education Study Program (Atalya Agustin)

to write things that went well. Moreover, $89 \%$ of the student teachers stated that they have written some resolution in their reflective journal. Most of the student teachers believe that all data whether they are strengths or weaknesses needs to be explained and analyzed for further follow-up. This, in fact, is aligned with the criteria that RJ help them to have initiative and self-control. They are willing to start examining their performance, able to manage their teaching and learning process, and they had power over their own practices.

This second domain also investigates student teachers' responses towards RJ. Student teachers' responses will be analyzed in their relations with meaningfulness or importance. $100 \%$ of them believe that writing RJ is important. Writing RJ was said to build awareness toward themselves, helps them to evaluate and reflect their teaching, gives them a picture of things they should change. It also can be a teaching journal so they can see their teaching progress. Furthermore, it shapes them to be reflective and become a responsive teacher. This is aligned with Shandomo (2010) who mentioned that reflective writing is a storyboard that helps student teachers infer everything that happens in their teaching and learning process. Student teachers could interpret what happens in the classroom and then take effective and efficient action. It also shows their true ability (strengths and weaknesses) and most importantly builds their critical thinking.

However, not all students (89\%) believes that writing RJ is meaningful for them. Even though writing RJ has many advantages such as becoming a mirror for them to reflect and enables them to see everything from different perspectives, some student teachers said that they wrote RJ because they were asked to. It is for the purpose of fulfilling course assignment. It is very difficult to do reflection because its unique trait which is finding assumption (Brookfield (1995). We, as human, normally have fear of what assumption we might discover within us when we reflect. Thus, we often do not really do reflection as it should be. Even though there are many evidence or data in the field, we do not take the opportunity to sincerely reflect for our betterment.

\section{Strengths And Challenges Of Writing Reflective Journal}

This domain related to the strengths and challenges arouse when student teachers were writing reflective journals. The figure below will show the percentage of each statement.

\section{THE STRENGTH AND CHALLENGES IN WRITING REFLECTIVE JOURNAL}

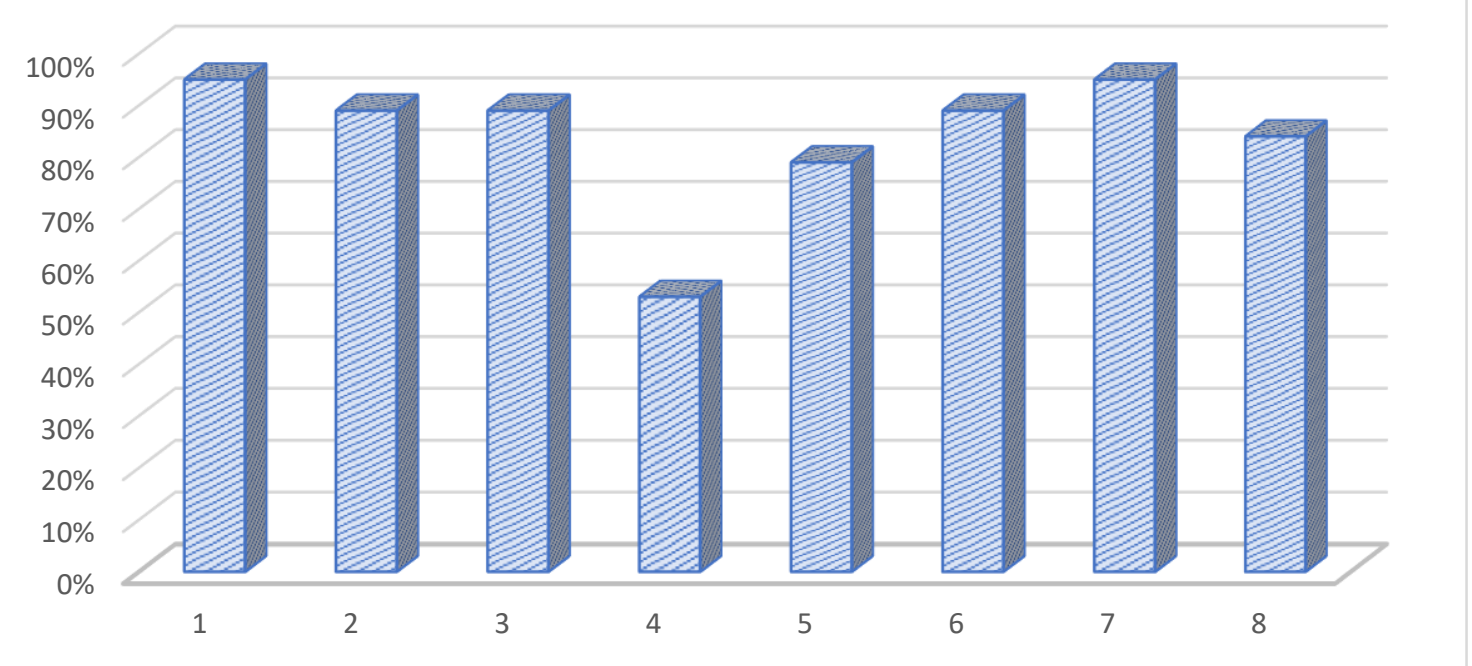

Annotation:

Figure 3. The Strengths and Challenges in Writing Reflective Journal

1. RJ help them to recognize their strength and weaknesses

2. helps them to rationale critical moments and respond to them

3. the rubrics helped guiding them

4. there was guidance from mentor or supervisor to write RJ 
5. she/he will keep writing RJ without being asked

6. writing RJ helps them to plan teaching and learning process

7. helps to bring change in terms of knowledge, skill and most importantly, perspective

8. writing RJ could strengthen their calling as teachers

The third domain is the strengths and challenges arise when they were writing RJ during their teaching practice. The student teachers are asked to write their reflective journal after teaching. They listed some strong points in regards of their teaching and learning process. Student teachers felt that writing RJ made them more reflective about their teaching quality and the reality in the field. 95\% student teachers agree that RJ help them to recognize their strength and weaknesses. It also helps them to rationale critical moments and respond to them (89\%). In conclusion, writing RJ helps them to analyze deeper and to be critical towards their teaching and learning process. Even though writing RJ is not an easy thing to do, student teachers were glad because there was rubrics for writing RJ. 89\% of the student teachers mentioned that the rubrics helped guiding them. However, only $53 \%$ of the students felt that there was guidance from mentor or supervisor to write RJ. It means that student teachers still need guidance from mentor or supervisor. This can be the challenge for student teachers because they need to be encouraged more to write their journal. They mentioned that they lacked confidence in doing so. The encouragement and guidance can be in the form of sharing or discussion which can help the student teachers to be more reflective. Input and suggestion from mentor or supervisor for RJ do matter.

Another challenge of writing a reflective journal is how to keep the habit going. 79\% student teachers mentioned that he/she will keep writing RJ without being asked. It shows that most of the student teachers could see how critical writing RJ is. The rest of them were probably writing RJ because they were asked to. It doesn't really mean that they didn't think that RJ is important. It is probably because of their habits. They were not used to do reflection especially in the written form. It is very crucial to build reflective habit for student teacher as this habit will help them a lot in their years to come as in-service teachers.

According to this study, student teachers understand the importance or meaningfulness of writing RJ but they need help and assistance in developing their habit. In fact, about $89 \%$ student teachers stated that writing RJ helps them to plan teaching and learning process. Furthermore, 95\% participants said that RJ helps to bring change in terms of knowledge, skill and most importantly, perspective. This condition really supports and is aligned with the fact that $84 \%$ of the student teachers felt that writing RJ could strengthen their calling as teachers. Being reflective and critical through writing RJ could make the student teachers see the meaningfulness of their profession. This awareness of meaningfulness could then lead to wisdom or a good sense to take action to be better. This is aligned with what Schön (1987) mentioned that what is needed by professional practitioner is not more professional insights but a good sense or prudence in putting the insights into practice. Teachers will be ready to face all the dynamic in the classroom and provide effective and efficient solution if they are growing in their calling as professional practitioner.

\section{CONCLUSION AND RECOMMENDATION}

The findings of the current study showed that student teachers recognized and experienced the importance or writing reflective journal towards their own development in teaching profession. The responses showed that most the student teachers were motivated and full of initiative in assessing their teaching and learning process. They also wanted to keep learning in order to acquire new insights and skills. Other professional issues identified in the student teachers' responses were the awareness of reflective and critical thinking and awareness of their own strength and weaknesses. Finally, some challenges pertaining building habit to write reflective journal and having mentor or supervisor to share the reflection with are subject to further follow-up. Thus, it is crucial for Teachers Colleges to make reflective journal as one of tools to evaluate students' concept and ability in teaching (Microteaching). Feedback can be given after the evaluation to find strategies to cope with any challenges as a professional teacher. 
Reflective Journal as A Self-Directed And Sustainable Professional Development Tool For Pre-Service Teachers: A Case Study In English Language Education Study Program (Atalya Agustin)

\section{REFERENCES}

Bassey, Michael. (1999). Case study research in educational settings. Buckingham: Open University Press.

Brookfield, Stephen. (1995). Becoming a Critically Reflective Teacher. San Fransisco: Jossey-Bass.

Farrel, Thomas.S.C. (2013). Reflective Teaching: English Language Teacher Development Series. Virginia: TESOL International Association.

Göker, S.D. (2016). Use of Reflective Journals in Development of Teachers' Leadership and Teaching

Skills, 4(12A), 63-70. Doi: 10. 13189/ujer.2016.041309.

Guskey, (2002). Professional development and teacher change. Teachers and Teaching: Theory and Practice, 8(3/4), 381-391. doi: 10.1080/135406002100000512.

Mulyana, D. (2010). Metodologi penelitian kualitatif: paradigma baru ilmu komunikasi dan ilmu sosial lainnya. Bandung: PT. Remaja Rosdakarya.

Lessing, A. \& de Witt, M. (2007). The value of continuous professional development: teachers' perceptions. South African Journal of Education, 27(1), 53-67. ISSN: 2076-3433.

Lingam, G., Lingam, N., \& Raghuwaiya, K. (2014). Professional development of pre-service teachers: the case of practicum experience. World Academy of Science, Engineering and Technology, 8 (7), 2134-2130. ISSN: 0950-4125.

Meng, Kathy. (2014). A Research on Self-Directed Professional Development of a Teacher of TESOL in Chinese Context. In Zheng, F (Ed.), Proceedings of International Conference on Global Economy, Finance and Humanities Research 2014 (pp. 52-55). Tianjin, China: Atlantis Press. ISBN: 978-94-6252-006-6.

Minnot, M. A. (2010). Reflective teaching as self-directed professional development: building practical or work-related knowledge. Professional Development in Education, 36(1-2), 325-338. doi: $10.1080 / 19415250903457547$.

Minott, M.A. (2010). Reflective Teaching and How it Aids in Coping with Heavy Workloads, Mandated Policies and Disagreements with Colleagues. Current Issues in Education, 13(1). Retrieved from http://cie.asu.edu/

Moon, Jennifer, A, (2005). A Handbook of reflective and experiential learning: theory and practice. New York: Routledge Falmer.

Schön, Donald, A. (1987). Educating the reflective practitioner: toward a new design for teaching and learning on the professions. San Francisco: Jossey-Bass Publishers.

Shandomo, Hibajene. E. (2010). The role of critical reflection in teacher education. ERIC: Institute of Education Sciences. 4(1), 101-113. 